\title{
Functional health literacy among undergraduate pharmacy students: a cross-sectional study from Pakistan
}

\begin{abstract}
Most of the medical and pharmacy students will work as health professionals after graduation and will have more opportunities to interact with patients. Therefore, they should possess adequate health literacy levels to enhance the health literacy of the patients.
\end{abstract}

Objective: The present study was designed to assess functional health literacy among undergraduate Pharm.D students studying at Hamdard University, Islamabad, Pakistan.

Methodology: A descriptive cross-sectional study design was used. A pre-validated tool S. Tofhla was self-administered to a sample of 400 Pharm.D students of Hamdard University, Islamabad, Pakistan. After data collection, data was cleaned coded and entered in SPSS version 21.0. Descriptive statistics comprising of frequency and percentages was calculated. The non-parametric tests including Mann-Whitney and Kruskal-Walis $(\mathrm{p} \geq 0.05)$ were performed to find out the difference among different variables.

Results: The results highlighted that female students had higher scores of functional health literacy $(29.03, \pm 4.14)$. Undergraduate students living in urban settings (28.69, \pm 4.66 ) had high functional health literacy scores than students living in rural areas $(26.46, \pm 6.48)$. Students having English language as medium of instruction during their schooling had better scores $(28.53, \pm 5.11)$ than students having Urdu language as medium of instruction in high school.

Conclusion: The results of the present study concluded that the level of functional health literacy among undergraduate pharmacy students was adequate. High level of health literacy is required to assist pharmacists to manage self-care activities, and the care of their patients, future research should be designed to explore whether improved health literacy amongst pharmacists transforms into improved self-care and better patient outcomes.

Keywords: health literacy, health behavior, university students, pharmacy education, pakistan, s-tofhla
Volume 5 Issue 5 - 2017

\author{
Madeeha Malik, Ayisha Hashmi, Junaid Khalid, \\ Mateen Abbas \\ Hamdard Institute of Pharmaceutical Sciences, Hamdard \\ University, Pakistan
}

\begin{abstract}
Correspondence: Madeeha Malik, Hamdard Institute of Pharmaceutical Sciences, Hamdard University, Islamabad, Pakistan,Email madeehamalikı5@gmail.com
\end{abstract}

Received: September 12, 2017 | Published: October 04, 2017

\section{Introduction}

Health literacy is considered to be a matrix of cognitive abilities comprised of four competency areas which include accessing, understanding, judging and applying information related to health. Each of these proficiencies is framed within three domains of health that characterize both individual and societal level interactions within the health system. These are healthcare, disease prevention and health promotion. ${ }^{1}$ The quality of health services and healthcare providers may be affected by health literacy levels of individuals. ${ }^{2}$ Most of the individuals have difficulty in navigating healthcare options and are unable to understand the information provided by health care professionals regardless of their education and social status. $^{3}$ The inability to comprehend health related information by the patient leads to ineffective self-management of their medical problems. Lack of knowledge and appropriate clinical skills among medical and nursing graduates required for addressing the needs of individuals with low health literacy leads to further aggravation of the health issue. ${ }^{4}$ Healthcare providers should possess adequate levels of health literacy for establishing an effective patient-provider communication relationship, as healthcare professionals can help in improving literacy levels of patients. Limited research has been conducted regarding levels of health literacy among healthcare professionals. Major gaps have been identified in the current literature among health professionals regarding their knowledge and clinical recognition of low health literacy. Great attention is required towards improving health literacy levels of medical and pharmacy students as after graduation they are involved in direct patient care. Interventions have been designed to improve health literacy levels in many countries but mostly have focused on patients, residents, and non-medical students. ${ }^{5}$ The current literacy rate in Pakistan is only $54.9 \%$ but little focus has been given to the issue of health literacy in the country. Globally one of the key players and readily available healthcare professionals are pharmacists. During their course of study, pharmacists must be equipped with the necessary clinical skills required to evaluate and address health literacy issues of patient's. ${ }^{6}$ Review of the existing literature has revealed that limited studies have been conducted regarding assessment of health literacy levels of pharmacy students. Studies have mostly focused on levels of health literacy of undergraduate students acquiring non-healthcare degrees in developed countries. Low levels of health literacy among pharmacy students may have negative impacts on the self-care abilities as well as 
on pharmaceutical care activities provided by them. There is a dire need for assessment of levels of health literacy among pharmacy students. ${ }^{5}$ To the best of our knowledge, no research has been conducted till date which has assessed health literacy among undergraduate pharmacy students. Thus, the present study was designed to assess functional health literacy among undergraduate Pharm.D students studying at Hamdard University, Islamabad, Pakistan.

\section{Methodology}

A descriptive cross-sectional study design was used to assess functional health literacy among undergraduate Pharm.D students studying at Hamdard University, Islamabad, Pakistan. National bioethical committee is present for this type of research and it states that only institutional head approval is required for this type of study. For data collection approval from Head of the Institute was taken. Informed and verbal consent for participation was also taken from the respondents. Respondents were ensured for the confidentiality of information verbally as well as confidentiality under taking was signed by the principal investigator. All the current Pharm.D students at Hamdard Institute of Pharmaceutical Sciences willing to participate were included in the study.

\section{Sample size and sampling procedure}

Calculation of sample size was performed by using Rao sof sample size calculator to determine the size of sample representing the population of Pharm.D students. Sample size was calculated as 400 to achieve $95 \%$ confidence interval with $5 \%$ margin of error. Convenience sampling technique was used to select the respondents. According to convenience sampling all the respondents that were available at time of data collection were selected.

\section{Data collection tool}

A pre-validated tool named S-TOFHLA was used to assess the functional health literacy among undergraduate students. S-TOFHLA (Reading Comprehension) tests a person's ability to read materials from the health care setting. It comprises of 2 functional health reading comprehension passages. Passage A is regarding X-ray preparation and passage $\mathrm{B}$ is about Medicaid rights and responsibilities. The passages are ordered by increasing difficulty. This is a timed test and should be stopped at the end of 7 minutes. Test comprises of 36 blanks (16 blanks in passage A, 20 blanks in passage B) to be filled by the most appropriate word among the 4 options given below each blank. Section one comprising of demographics was filled by the respondents. Section two is where the S-TOFHLA test started. The test was printed in 14 point font (large print) in order to avoid difficulty in reading. Scoring of tool is done by comparing the answers with the appropriate scoring key provided. In the score box, "1" was circled for correct and " 0 " for incorrect for each blank. Correct answers were summed for each page and total was recorded on the last scoring column page as the Reading Comprehension Raw Score and then it was seen that the score lies in which of the mentioned ranges given in the TOFHLA Functional Health Literacy Levels (Table 1).

\section{Reliability and validity of the tool}

Two focused group discussions had been conducted at different time intervals with experts from hospitals, regulatory authorities and academia for face and content validation of the tool. Beside this pilot testing was conducted at $10 \%$ of the sample size to test the reliability of the tool. Value of Cronbach alpha for the tool was 0.88 which was satisfactory.
Table I TOFHLA functional health literacy levels

\begin{tabular}{lcl}
\hline Levels & $\begin{array}{l}\text { Tofhla } \\
\text { score }\end{array}$ & $\begin{array}{l}\text { Functional health literacy } \\
\text { description }\end{array}$ \\
\hline $\begin{array}{l}\text { Inadequate } \\
\text { Functional Health } \\
\text { Literacy }\end{array}$ & $0-16$ & $\begin{array}{l}\text { Unable to read and interpret } \\
\text { health texts }\end{array}$ \\
$\begin{array}{l}\text { Marginal Functional } \\
\text { Health Literacy }\end{array}$ & $17-22$ & $\begin{array}{l}\text { Has difficulty reading and } \\
\text { interpreting health texts }\end{array}$ \\
$\begin{array}{l}\text { Adequate Functional } \\
\text { Health Literacy }\end{array}$ & $23-36$ & $\begin{array}{l}\text { Can read and interpret most } \\
\text { health texts }\end{array}$ \\
\hline
\end{tabular}

\section{Data collection and analysis}

Data was collected by the investigators. The respondents were identified and after obtaining written/verbal consent from them, the questionnaire was hand delivered to them. The questionnaire was collected back on the same day to avoid study biasness. After data collection, data was cleaned coded and entered in SPSS version 21.0. Skewness test was performed and histograms with normal curves were used to check the normal distribution of data. Descriptive statistics comprising of frequency and percentages was calculated. The non-parametric tests including Mann-Whitney and Kruskal-Walis $(\mathrm{p} \geq 0.05)$ were performed to find out the difference among different variables.

\section{Results}

\section{Demographic characteristics}

Out of 400 respondents, $30.5 \%(n=122)$ were males and $69.5 \%$ $(n=278)$ were females. Of the total respondents $44.2 \% \quad(n=177)$ were less than 20years of age whereas $55.7 \%(n=223)$ were between $20-30$ years of age. Of the total respondents, $77.2 \%(n=309)$ had studied in an English medium high school whereas $22 \%(n=88)$ had studied in an Urdu medium high school. Of the total respondents, $23.7 \%(\mathrm{n}=95)$ were studying in 1 st professional, $18.5 \%(\mathrm{n}=74)$ in $2 \mathrm{nd}$ professional, $17.7 \%(n=71)$ in $3 r d$ professional, $22 \%(n=88)$ in 4 th professional and $18 \%(n=72)$ in 5 th professional (Table 2).

\section{Levels of health literacy by different demographic cha- racteristics among undergraduate pharmacy students}

The results highlighted that majority of the males had adequate health literacy $(78.6 \%, n=96), 8.1 \%(n=10)$ had marginal whereas $13.1 \%(\mathrm{n}=16)$ had inadequate health literacy. Among female respondents, $93.5 \%(\mathrm{n}=260)$ had adequate health literacy, 3.5\% $(\mathrm{n}=10)$ had marginal and $2.8 \%(n=8)$ had inadequate health literacy. Majority of students aged less than 20years had adequate health literacy $(88.1 \%, n=156)$ whereas $89.6 \%(n=200)$ of the students aged between 20-30years had adequate health literacy. The results highlighted that majority of the students residing in Islamabad had adequate health literacy $(91.9 \%, n=148)$ whereas only $4.9 \%(n=8)$ had inadequate literacy levels. Majority of the students living in Rawalpindi had high literacy levels $(86.9 \%, n=133)$ whereas only $5.8 \%(n=9)$ had inadequate literacy levels. About $90.2 \%(n=279)$ having English as medium of instruction had adequate literacy levels whereas $85.2 \%$ $(\mathrm{n}=75)$ having Urdu language as medium of instruction had adequate health literacy levels. The results highlighted that $86.3 \%(n=82)$ of students studying in 1 st professional had adequate health literacy, $81.08 \%(\mathrm{n}=60)$ in $2 \mathrm{nd}$ professional, $87.3 \%(\mathrm{n}=62)$ in 3rd professional, 
$94.3 \%(\mathrm{n}=83)$ in 4 th professional and $95.8 \%(\mathrm{n}=69)$ in 5 th professional had adequate health literacy levels (Table 3 ).

Table 2 Demographic characteristics

\begin{tabular}{|c|c|}
\hline Variable & $\mathbf{n}(\%)$ \\
\hline \multicolumn{2}{|l|}{ Gender } \\
\hline Male & $122(30.5 \%)$ \\
\hline Female & $278(69.5 \%)$ \\
\hline \multicolumn{2}{|l|}{ Age } \\
\hline$<20$ years & $177(44.2 \%)$ \\
\hline 20-30years & $223(55.7 \%)$ \\
\hline \multicolumn{2}{|l|}{ City } \\
\hline Islamabad & $161(40.2 \%)$ \\
\hline Rawalpindi & $153(38.2 \%)$ \\
\hline Wah/Taxila & $20(5 \%)$ \\
\hline Other(KPK and other cities of Punjab) & $66(16.5 \%)$ \\
\hline \multicolumn{2}{|l|}{ Setting } \\
\hline Urban & $327(81.7 \%)$ \\
\hline Rural & $73(18.2 \%)$ \\
\hline \multicolumn{2}{|l|}{ Medium of instruction in high school } \\
\hline English & $309(77.2 \%)$ \\
\hline Urdu & $88(22 \%)$ \\
\hline \multicolumn{2}{|l|}{ Current professional of Pharm.D } \\
\hline Ist professional & $95(23.7 \%)$ \\
\hline $2^{\text {nd }}$ professional & $74(18.5 \%)$ \\
\hline $3^{\text {rd }}$ professional & $71(17.7 \%)$ \\
\hline $4^{\text {th }}$ professional & $88(22 \%)$ \\
\hline $5^{\text {th }}$ professional & $72(18 \%)$ \\
\hline \multicolumn{2}{|l|}{ Parents income } \\
\hline$<$ Rs. 10,000 & $17(4.2 \%)$ \\
\hline Rs. $10,000-20,000$ & $28(7 \%)$ \\
\hline Rs. $21,000-30,000$ & $27(6.7 \%)$ \\
\hline Rs. $31,000-40,000$ & $16(4 \%)$ \\
\hline Rs. $41,000-50,000$ & $17(4.2 \%)$ \\
\hline$>$ Rs. 50,000 & $33(8.2 \%)$ \\
\hline Not responded & $262(65.5 \%)$ \\
\hline
\end{tabular}

Mean scores of health literacy by different demographic characteristics among undergraduate pharmacy students

The results highlighted that female students had higher scores of functional health literacy $(29.03 \pm 4.14)$. Students aged between $20-30$ years had slightly higher score $(28.37 \pm 5.21)$. Students living in Wah and Taxila had higher scores $(29.60, \pm 2.72)$ than students living in other cities. Undergraduate students living in urban settings (28.69, \pm 4.66 ) had high functional health literacy scores than students living in rural areas $(26.46, \pm 6.48)$. Students having English language as medium of instruction during their schooling had better scores (28.53, \pm 5.11 ) than students having Urdu language as medium of instruction in high school (Table 4).
Table 3 Levels of health literacy by different demographic characteristics among undergraduate pharmacy students

\begin{tabular}{|c|c|c|c|}
\hline Variables & $\begin{array}{l}\text { Inadequate } \\
\text { functional } \\
\text { health literacy } \\
\mathrm{n}(\%)\end{array}$ & $\begin{array}{l}\text { Marginal } \\
\text { functional } \\
\text { health } \\
\text { literacy } n(\%)\end{array}$ & $\begin{array}{l}\text { Adequate } \\
\text { functional } \\
\text { health } \\
\text { literacy } n(\%)\end{array}$ \\
\hline \multicolumn{4}{|l|}{ Gender } \\
\hline Male & $16(13.1 \%)$ & $10(8.1 \%)$ & $96(78.6 \%)$ \\
\hline Female & $8(2.8 \%)$ & $10(3.5 \%)$ & $260(93.5 \%)$ \\
\hline \multicolumn{4}{|l|}{ Age } \\
\hline$<20$ years & $9(5 \%)$ & $12(6.7 \%)$ & $156(88.1 \%)$ \\
\hline 20-30years & $15(6.7 \%)$ & $8(3.5 \%)$ & $200(89.6 \%)$ \\
\hline \multicolumn{4}{|l|}{ City } \\
\hline Islamabad & $8(4.9 \%)$ & $5(3.1 \%)$ & |48(9|.9\%) \\
\hline Rawalpindi & $9(5.8 \%)$ & II(7.I\%) & |33(86.9\%) \\
\hline Wah/Taxila & 0 & $\mathrm{I}(5 \%)$ & $19(95 \%)$ \\
\hline $\begin{array}{l}\text { Other(KPK and } \\
\text { other cities of } \\
\text { Punjab) }\end{array}$ & $7(10.6 \%)$ & $3(4.5 \%)$ & $56(84.8 \%)$ \\
\hline \multicolumn{4}{|l|}{ Setting } \\
\hline Urban & $15(4.5 \%)$ & $14(4.2 \%)$ & 298(91.1\%) \\
\hline Rural & $9(12.3 \%)$ & $6(8.2 \%)$ & $58(79.4 \%)$ \\
\hline \multicolumn{4}{|l|}{$\begin{array}{l}\text { Medium of } \\
\text { instruction in } \\
\text { high school }\end{array}$} \\
\hline English & $17(5.5 \%)$ & $13(4.2 \%)$ & $279(90.2 \%)$ \\
\hline Urdu & $6(6.8 \%)$ & $7(7.9 \%)$ & $75(85.2 \%)$ \\
\hline \multicolumn{4}{|l|}{$\begin{array}{l}\text { Current } \\
\text { professional } \\
\text { of Pharm.D }\end{array}$} \\
\hline Ist professional & $7(7.3 \%)$ & $6(6.3 \%)$ & $82(86.3 \%)$ \\
\hline 2nd professional & $6(8.1 \%)$ & $8(10.8 \%)$ & $60(81.08 \%)$ \\
\hline 3rd professional & $7(9.8 \%)$ & $2(2.8 \%)$ & $62(87.3 \%)$ \\
\hline 4th professional & $4(4.5 \%)$ & $\mathrm{I}(\mathrm{I} .1 \%)$ & $83(94.3 \%)$ \\
\hline 5th professional & 0 & $3(4.1 \%)$ & $69(95.8 \%)$ \\
\hline \multicolumn{4}{|l|}{$\begin{array}{l}\text { Parents } \\
\text { income }\end{array}$} \\
\hline$<$ Rs. 10,000 & $3(17.6 \%)$ & $2(11.7 \%)$ & $12(70.5 \%)$ \\
\hline $\begin{array}{l}\text { Rs. } 10,000 \text { - } \\
20,000\end{array}$ & $2(7.1 \%)$ & $2(7.1 \%)$ & $24(85.7 \%)$ \\
\hline $\begin{array}{l}\text { Rs.21,000- } \\
30,000\end{array}$ & $\mathrm{I}(3.7 \%)$ & $2(7.4 \%)$ & $24(88.8 \%)$ \\
\hline $\begin{array}{l}\text { Rs.31,000- } \\
40,000\end{array}$ & $\mathrm{I}(6.2 \%)$ & $2(12.5 \%)$ & $13(81.2 \%)$ \\
\hline $\begin{array}{l}\text { Rs. } 41,000 \text { - } \\
50,000\end{array}$ & $2(11.7 \%)$ & $\mathrm{I}(5.8 \%)$ & I4(82.3\%) \\
\hline$>$ Rs. 50,000 & $6(18.1 \%)$ & $\mathrm{I}(3 \%)$ & $26(78.7 \%)$ \\
\hline Not responded & $9(3.4 \%)$ & $10(3.8 \%)$ & $243(92.7 \%)$ \\
\hline
\end{tabular}


Table 4 Mean scores of health literacy by different demographic characteristics among undergraduate pharmacy students

\begin{tabular}{|c|c|}
\hline Variables & $\begin{array}{l}\text { Mean functional health } \\
\text { literacy scores } \\
\text { (Score: inadequate-0-16, } \\
\text { marginal-17-22, } \\
\text { adequate-23-36) }\end{array}$ \\
\hline \multicolumn{2}{|l|}{ Gender } \\
\hline Male & $26.72( \pm 6.43)$ \\
\hline Female & $29.03( \pm 4.14)$ \\
\hline \multicolumn{2}{|l|}{ Age } \\
\hline$<20$ years & $28.20( \pm 4.97)$ \\
\hline $20-30$ years & $28.37( \pm 5.21)$ \\
\hline \multicolumn{2}{|l|}{ City } \\
\hline Islamabad & $28.62( \pm 4.92)$ \\
\hline Rawalpindi & $28.16( \pm 5.28)$ \\
\hline Wah/Taxila & $29.60( \pm 2.72)$ \\
\hline $\begin{array}{l}\text { Other(KPK and other } \\
\text { cities of Punjab) }\end{array}$ & $27.9( \pm 6.26)$ \\
\hline \multicolumn{2}{|l|}{ Setting } \\
\hline Urban & $28.69( \pm 4.66)$ \\
\hline Rural & $26.46( \pm 6.48)$ \\
\hline \multicolumn{2}{|c|}{$\begin{array}{l}\text { Medium of instruction } \\
\text { in high school }\end{array}$} \\
\hline English & $28.53( \pm 5.11)$ \\
\hline Urdu & $27.40( \pm 5.03)$ \\
\hline \multicolumn{2}{|c|}{$\begin{array}{l}\text { Current professional of } \\
\text { Pharm.D }\end{array}$} \\
\hline Ist professional & $27.67( \pm 5.47)$ \\
\hline 2nd professional & $27.37( \pm 6.24)$ \\
\hline 3rd professional & $28.30( \pm 5.32)$ \\
\hline 4th professional & $29.04( \pm 4.43)$ \\
\hline 5th professional & $29.22( \pm 3.29)$ \\
\hline \multicolumn{2}{|l|}{ Parents income } \\
\hline$<$ Rs. 10,000 & $25.05( \pm 8.34)$ \\
\hline Rs. $10,000-20,000$ & $27.57( \pm 5.17)$ \\
\hline Rs.21,000-30,000 & $28.00( \pm 4.80)$ \\
\hline Rs.3I,000-40,000 & $28.37( \pm 6.11)$ \\
\hline Rs. $41,000-50,000$ & $27.64( \pm 6.37)$ \\
\hline$>$ Rs. 50,000 & $26.24( \pm 7.17)$ \\
\hline Not responded & $28.89( \pm 4.25)$ \\
\hline
\end{tabular}

\section{Comparison of functional health literacy of Pharm.D students by demographic characteristics}

A significant difference $(p \geq 0.05)$ in functional health literacy of Pharm.D students was observed among different gender, setting and medium of schooling. Female students had relatively better functional health literacy than male students while students living in urban areas and having English language as medium of schooling possessed better functional health literacy. On the other hand, no significant difference $(\mathrm{p} \geq 0.05)$ with respect to different professionalyears, city of residence and parent's income was observed (Table 5).

Table 5 Comparison of functional health literacy of Pharm.D students by demographic characteristics

\begin{tabular}{|c|c|c|c|c|}
\hline \multirow[t]{2}{*}{ Demographics } & \multicolumn{4}{|c|}{ Functional health literacy score } \\
\hline & $\mathbf{n}$ & $\begin{array}{l}\text { Mean } \\
\text { rank }\end{array}$ & $\begin{array}{l}\text { Test } \\
\text { statistics }\end{array}$ & p-value \\
\hline \multirow[t]{2}{*}{ Gender } & Male $=122$ & 172.6 & \multirow{2}{*}{$13747.500^{\mathrm{a}}$} & \multirow{2}{*}{0.001} \\
\hline & Female $=278$ & 213.1 & & \\
\hline \multirow[t]{2}{*}{ Setting } & Rural $=73$ & 166.8 & \multirow{2}{*}{$9099.500^{\mathrm{a}}$} & \multirow{2}{*}{0.004} \\
\hline & Urban $=327$ & 207.5 & & \\
\hline \multirow[t]{2}{*}{$\begin{array}{l}\text { Medium of } \\
\text { schooling }\end{array}$} & English=309 & 208.8 & \multirow[t]{2}{*}{$11250.0^{\mathrm{a}}$} & \multirow[t]{2}{*}{0.005} \\
\hline & Urdu $=88$ & 171.5 & & \\
\hline \multirow[t]{5}{*}{$\begin{array}{l}\text { Professional } \\
\text { Year }\end{array}$} & Ist Prof $=95$ & 188.77 & \multirow{5}{*}{$4.26^{\mathrm{b}}$} & \multirow{5}{*}{0.371} \\
\hline & 2nd Prof $=74$ & 188.9 & & \\
\hline & $3 r d$ Prof $=71$ & 201.56 & & \\
\hline & 4th Prof $=88$ & 217.63 & & \\
\hline & 5th Prof $=72$ & 207.91 & & \\
\hline \multirow[t]{5}{*}{$\begin{array}{l}\text { City of } \\
\text { residence }\end{array}$} & Islamabad=|6| & 204.18 & \multirow{5}{*}{$8108.0^{\mathrm{b}}$} & \multirow{5}{*}{0.88} \\
\hline & Rawalpindi $=153$ & 197.98 & & \\
\hline & Wahcantt $=20$ & 130.87 & & \\
\hline & $\mathrm{KPK}=20$ & 214.35 & & \\
\hline & Punjab $=46$ & 192.3 & & \\
\hline
\end{tabular}

Mann Whittney'; Kruskal Wallis Test ${ }^{\mathrm{b}}(\mathrm{p} \geq 0.05)$

\section{Discussion}

The overall success in achieving desired treatment outcomes profoundly relies on high literacy levels of individuals. Inadequate health literacy contributes to diminished treatment outcomes owing to patient's inability to evaluate and utilize health care system, to attend health appointments, to comprehend health related documents, and to follow prescription directions and drug therapy plan. There is a requirement of improved health literacy training for all students acquiring healthcare degree as students must be prepared effectively for communicating with low health literacy patients in order to achieve maximum clinical outcomes. ${ }^{7}$ The results of the present study are quite encouraging as they showed that majority of the undergraduate pharmacy students had adequate functional health literacy. The results of the current study highlighted that female students had relatively better functional health literacy as compared to male students. This might be due to the fact that females are more conscious regarding their health and generally possess better academic scores. The results are in line with findings of a study conducted in china where female 
college students reported higher knowledge regarding health. ${ }^{8}$ The results of the study highlighted that students living in urban areas and having English as their medium of instruction at high school had higher health literacy scores than students living in rural areas. This might be due to the fact that people living in urban areas have more access and better healthcare \& education facilities due to which they are comparatively well informed and conscious regarding their health. Similar findings were reported from studies conducted in colleges and medical universities of China..$^{5-8}$ The results of the present study highlighted that students studying in the final professional had better functional health literacy than students studying in first and second professionals of Pharm.D. Similar findings were reported in studies conducted in Britain, Indonesia and china which concluded that health literacy scores were linked with year of study. ${ }^{5-9}$ The results of the current study revealed that students whose parents income was between Rs.31,000-40,000 had highest scores of functional health literacy whereas students having lower financial income had low scores. The results are in line with studies conducted in Britain, china and Greece. ${ }^{8-10}$

\section{Conclusion}

The results of the present study concluded that the level of functional health literacy among undergraduate pharmacy students was adequate. Students living in urban areas and with better educational background possessed better functional health literacy. Health literacy is one of the basic foundations of public health policy; therefore, collaborative working of different stakeholders is required to develop effective interventions for improving functional health literacy among residents of rural areas. Furthermore, based on the premise that a high level of health literacy is required to assist pharmacists to manage self-care activities, and the care of their patients, future research should be designed to explore whether improved health literacy amongst pharmacists transforms into improved self-care and better patient outcomes.

\section{Acknowledgements}

None.

\section{Conflict of interest}

Author declares that there is no conflict of interest.

\section{References}

1. Runk L, Durham J, Vongxay V, et al. Measuring health literacy in university students in Vientiane, Lao PDR. Health Promot Int. 2017;32(2):360-368.

2. Rowlands G, Shaw A, Jaswal S, et al. Health literacy and the social determinants of health: a qualitative model from adult learners. Health Promot Int. 2017;32(1):130-138.

3. Davis TC, Wolf MS. Health literacy: Implications for family medicine. Fam Med. 2004;36(8):595-598.

4. Coleman C. Teaching health care professionals about health literacy: A review of the literature. Nurs Outlook. 2011;59(2):70-78.

5. Zhang Y, Zhang F, Hu P, et al. Exploring health literacy in medical university students of Chongqing, China: A cross-sectional study. PloS one. 2016;11(4):e0152547.

6. Mnatzaganian C, Fricovsky E, Best BM, et al. An Interactive, Multifaceted Approach to Enhancing Pharmacy Students' Health Literacy Knowledge and Confidence. Am J Pharm Educ. 2017;81(2):32.

7. Mullan J, Burns P, Weston K, et al. Health Literacy amongst Health Professional University Students: A Study Using the Health Literacy Questionnaire. Educ Sci. 2017;7(2):54.

8. Wang W, Hou Y, Hu N, et al. A cross-sectional study on health-related knowledge and its predictors among Chinese vocational college students. BMJ Open. 2014;4(10): 005182.

9. Lestari P, Handiyani H. The higher level of health literacy among health students compared with non-health students. UI Proc Health Med. 2017;2:141.

10. Von Wagner C, Knight K, Steptoe A, et al. Functional health literacy and health-promoting behaviour in a national sample of British adults. $J$ Epidemiol Community Health. 2007;61(12):1086-1090. 